УДК 336.02

\title{
С.Ф. Федулова
}

\section{ФИНАНСОВАЯ ПОДДЕРЖКА МАЛОГО И СРЕДНЕГО БИЗНЕСА В УДМУРТСКОЙ РЕСПУБЛИКЕ}

Рассматриваются различные формы и методы финансовой поддержки малого и среднего бизнеса в Удмуртской Республике, а также организации, предоставляющие такую поддержку и условия её предоставления. Автор уделил внимание региональной Подпрограмме «Развитие малого и среднего предпринимательства в Удмуртской Республике», условиям предоставления микрозаймов, тендерного финансирования, кредитования под контракт, посредничества в предоставлении банковских гарантий, поддержки предпринимателей в рамках льготного лизинга оборудования, кредитования проектов, направленных на развитие импортозамещения субъектов малого и среднего бизнеса микрокредитной организацией «Удмуртский фонд развития предпринимательства». Проведён анализ объёмов финансирования, количества заявленных и профинансированных проектов, структуры финансирования Удмуртским фондом развития предпринимательства субъектов малого и среднего бизнеса в отраслевом разрезе. Рассмотрен состав кредиторов и объёмы кредитов и поручительств Гарантийного фонда содействия кредитованию субъектов малого и среднего бизнеса, а также формы финансовой поддержки предпринимателей в секторе малого и среднего бизнеса, оказываемые республиканским бизнес-инкубатором (аренда помещений на льготных условиях с оплатой содержания помещений, консалтинговая поддержка по финансовым и юридическим вопросам ведения бизнеса).

Ключевые слова: субъекты малого и среднего бизнеса, финансовая поддержка, микрозаймы, тендерное финансирование, кредитование под контракт, посредничество в предоставлении банковских гарантий, кредитование проектов.

\section{DOI: $10.35634 / 2412-9593-2019-29-6-771-775$}

В Удмуртской Республике, так же как и в целом по России, реализуется ряд программ по финансовой поддержке малого предпринимательства. В Республике реализуется Подпрограмма «Развитие малого и среднего предпринимательства в Удмуртской Республике», действуют Удмуртский фонд государственной поддержки малого предпринимательства, Гарантийный фонд содействия кредитованию Малого и среднего предпринимательства Удмуртской Республики (далее - МСП), другие организации и формы поддержки МСП. Подпрограмма «Развитие малого и среднего предпринимательства в Удмуртской Республике» является составной частью Государственной программы Удмуртской Республики «Создание условий для устойчивого экономического развития Удмуртской Республики» и призвана создать необходимые условия для государственной финансовой поддержки МСП, содействовать развитию последнего, повышать эффективность инфраструктуры поддержки МСП, содействовать вовлечению населения, особенно молодёжи, в предпринимательскую деятельность. Подпрограмма реализуется в 2013-2020 гг. и для её реализации из бюджета Удмуртской Республики выделялось и будет выделено в будущем ассигнований на общую сумму 286 883,1 тыс. рублей. При реализации государственных программ устанавливаются целевые показатели (индикаторы) реализации этих программ и только в случае их выполнения осуществляется дальнейшее финансирование, что стимулирует МСП и органы государственной власти к эффективному использованию бюджетных и других финансовых ресурсов. При всех положительных сторонах программного финансирования проектов имеются и минусы (формальный подход к разработке целевых показателей по некоторым программам, их корректировка при изменении объёмов финансирования, невыполнение планов финансирования, неудовлетворительное состояние выполнения некоторых программ) [1]. Основными индикаторами вышеназванной подпрограммы являются: количество малых и средних предприятий, а также индивидуальных предпринимателей в расчете на 1 тысячу человек населения Удмуртской Республики; количество новых рабочих мест, созданных субъектами МСП и доля работников МСП в общей численности занятого населения; прирост оборота продукции и услуг, производимых МСП [2].

За счёт выполнения этих индикаторов осуществляется взаимодействие МСП с бюджетом, субъекты МСП, получив финансовую поддержку, увеличивают объёмы производимой продукции, выручку от реализации, а значит и платежи в бюджет. По данным Министерства финансов Удмуртской 
Республики оборот продукции (услуг), производимой малыми предприятиями и индивидуальными предпринимателями, в рамках вышеназванной государственной программы с 2017 по 2021 г. должен вырасти с 465,9 до 541,1 млрд рублей или на $16 \%{ }^{1}$

Бюджетные средства в рамках подпрограммы выделяются на определённые цели. На 2018 2020 гг. предусматривались следующие направления финансирования:

- поддержка и стимулирование развития МСП;

- сдача субъектам МСП на льготных условиях в аренду движимого и недвижимого имущества;

- оказание на льготных условиях услуг по информационному обеспечению;

- предоставление субсидий на уплату земельного налога.

Кроме указанных направлений планировалось предоставление государственных гарантий Удмуртскому государственному фонду поддержки малого предпринимательства в обеспечение исполнения обязательств перед кредитными учреждениями. Однако в связи с изменением бюджетной политики Удмуртской Республики, принятием с 2018 г. курса на профицитный бюджет и снижение государственного долга, на 2019-2021 г. Законом о бюджете Удмуртской Республики предоставление государственных гарантий не предусмотрено ${ }^{2}$. Следует отметить, что на цели реализации подпрограммы предполагается привлечение средств федерального бюджета. В связи с чем планируется ежегодное участие Удмуртской Республики в конкурсах по отбору субъектов Российской Федерации, бюджетам которых предоставляются субсидии на реализацию мероприятий по поддержке малого и среднего предпринимательства. Ориентировочно объем субсидий из федерального бюджета оценивается в сумме более 700 млн руб.

Одним из основных участников отношений финансирования МСП является Удмуртский фонд развития предпринимательства (далее УФРП), созданный 15 декабря 1995 г. по распоряжению Правительства Удмуртской Республики. В 2011 г. Министерством финансов РФ УФРП был присвоен статус микрофинансовой организации, в настоящее время фонд является микрокредитной организацией. Главной задачей УФРП является оказание финансовой поддержки малому и среднему бизнесу на основе предоставления микрозаймов. В рамках своей деятельности УФРП оказывает также услуги по тендерному финансированию, кредитованию исполнения контракта и выдаче банковских гарантий, льготному лизингу, финансовой поддержке экспорта, инжиниринговые услуги [3].

Микрозаймы предоставляются фондом в сумме до 2 млн руб. на срок до 36 месяцев под 6-10 \% годовых. Для получения микрозайма предприниматель должен подать в УФРП заявление, оформить необходимый пакет документов и в течение 30 дней фонд принимает решение о выдаче или отказе в выдаче займа. В соответствии с отчётами о деятельности фонда в 2017 г. ставка кредитования в размере $6 \%$ применялась для инновационных компаний, субъектов социального предпринимательства и предпринимателей, имеющих инвалидность, начинающих предпринимателей, сельскохозяйственных компаний; ставка 8 \% использовалась для предприятий отраслей охоты и лесного хозяйства, рыболовства и рыбоводства, обрабатывающих производств, а для СМП, занимающихся видами деятельности, не указанными выше, - 10 \%. В 2018 г. ставки дифференцировались по двум группам: для СМП, действующих в сфере социального предпринимательства, и предпринимателей, имеющих инвалидность, для начинающих предпринимателей, для покупателей франшиз, для сельскохозяйственных компаний использовалась ставка $6 \%$; для других СМП - 7,5 \% [4; 5].

В рамках тендерного финансирования УФРП оказывает услуги по предоставлению средств для участия в тендерах. При этом решение может быть принято за минимальное время (1 час), не требуется залог, оформляется минимальный пакет документов, займ беспроцентный, но взимается комиссионное вознаграждение в размере $3 \%$ и более в зависимости от условий займа. Максимальный срок займа - 60 дней.

УФРП также кредитует предпринимателей под контракт. В этом случае контракт выступает обеспечением займа, максимальная сумма займа составляет 30 млн руб., максимальный срок - 1,5 года, но не более срока самого контракта плюс два месяца. Плюсами данного договора является отсутствие залога, поскольку обеспечением займа является сам контракт и возможность получения крупной суммы займа. Минусом является высокая процентная ставка (минимум 16 \% годовых).

\footnotetext{
${ }^{1}$ Бюджет для граждан к закону Удмуртской Республики «О бюджете Удмуртской Республики на 2019 год и на плановый период 2020 и 2021 годов». URL: http://www.mfur.ru/budget\%20for\%20citizens/

${ }^{2}$ Бюджет для граждан к закону Удмуртской Республики «О бюджете Удмуртской Республики на 2019 год и на плановый период 2020 и 2021 годов». URL: http://www.mfur.ru/budget\%20for\%20citizens/
} 
Ещё одним направлением деятельности УФРП является посредничество в получении банковских гарантий. Гарантирована может быть сумма до 50 млн руб., но при этом цепочка от фонда до банка включает ещё несколько посредников и стоимость гарантий повышается. Стоит отметить, что УФРП с 2017 г. работает напрямую с АО «МСП Банк», который реализует разнообразные программы кредитования малого и среднего бизнеса. Кредиты могут быть выданы на срок до 7 лет на сумму до 1000 млн руб. Ставки различаются в диапазоне от 8,1 до 10,6 \% в зависимости от целей кредитования, но при кредитовании сельхозпроизводителей по программам Министерства сельского хозяйства ставка может быть снижена до $1 \%$. Банк сотрудничает также с Министерством экономического развития, по программам которого ставка составляет 6,5 \% годовых [6].

УФРП оказывает поддержку предпринимателям в рамках льготного лизинга оборудования. Президиумом Совета при Президенте Российской Федерации по стратегическому развитию и приоритетным проектам в 2016 г. утвержден паспорт приоритетного проекта «Малый бизнес и поддержка индивидуальной предпринимательской инициативы», которым предусмотрено создание в субъектах Российской Федерации региональных лизинговых компаний для реализации уставных целей АО «Корпорация «МСП», в первую очередь для развития индивидуального и малого предпринимательства, в рамках реализации программы льготного лизинга оборудования. В рамках программы льготного лизинга оборудование предоставляется субъектам индивидуального и малого предпринимательства по ставке $6 \%$ годовых (для отечественного оборудования) и $8 \%$ годовых (для иностранного оборудования). К 2019 г. лизинговые компании были созданы в Татарстане, Башкортостане, Ярославской области и Республике Саха. Сумма лизинга может варьироваться от 5 до 200 млн руб., срок от 13 месяцев до 7 лет. Предприятие - арендатор должно при заключении договора выплатить минимальный аванс от $10 \%$, а по некоторым программам лизинга от $15 \%$ суммы договора лизинга [7].

В рамках финансовой поддержки промышленности УФРП совместно с Российским фондом технологического развития кредитует проекты, направленные на развитие импортзамещения. Условием кредитования является долевое участия заёмщика в финансировании проекта и обеспечение кредита. Сумма займа может достигать 100 млн руб., минимальная ставка - $1 \%$, базовые ставки также невысокие и составляют 3 или $5 \%$ в зависимости от условий кредитования. Поскольку условия данного вида финансовой поддержки довольно привлекательны для предпринимателей, то получить этот вид поддержки достаточно сложно и предприниматели должны выполнить ряд условий, для того, чтобы именно их проекты были отобраны для финансирования.

Большая часть заявок, поданных субъектами СМП, удовлетворяется фондом. Так, в 2017 г. было подано 616 заявок на сумму 971300 тыс. руб., из них удовлетворено 489 заявок (79 \% от поданных) на сумму 697910 тыс. руб.(72 \% от заявленных сумм). Объёмы финансирования, предоставляемые УФРП имели растущую динамику с 2015 до 2018 г. (объёмы финансирования выросли с 465 до 697 млн руб. или на $50 \%$ ), а в 2018 г. в связи с изменением бюджетной политики Республики и сокращением бюджетного финансирования, объём финансирования проектов снизился на $5 \%$ до 661 млн руб. Количество профинансированных проектов в 2015 г. составило 544, в 2016 г. - 399, в 2017 г. - 489, а в 2018 г. 464 проекта, то есть наблюдается тенденция снижения.

Таблица 1

\section{Структура финансирования Удмуртского фонда развития предпринимательства в 2017 -2018 годах по отраслям}

\begin{tabular}{|l|c|c|c|c|}
\hline \multirow{2}{*}{ Отрасль } & \multicolumn{2}{|c|}{2017 г. } & \multicolumn{2}{c|}{2018 г. } \\
\cline { 2 - 5 } & Сумма, млн руб. & Доля, \% & Сумма, млн руб. & Доля, \% \\
\hline Торговля & 295 & 42 & 257 & 39 \\
\hline Услуги & 163 & 23 & 206 & 31 \\
\hline Производство & 163 & 23 & 132 & 20 \\
\hline Сельское хозяйство & 49 & 7 & 31 & 4,7 \\
\hline Строительство & 28 & 4 & 28 & 5 \\
\hline
\end{tabular}

Если предприниматель по каким-либо причинам не может воспользоваться вышеназванными формами финансовой поддержки УФРП, но планирует взять кредит в банке, то он может воспользоваться поручительством созданного в Удмуртской Республике Гарантийного фонда содействия кредитованию малого и среднего предпринимательства Удмуртии. Фонд может предоставить поручительст- 
во в размере до 70 \% от суммы кредита на срок до 15 лет. В основном доля поручительств составляет около половины суммы выдаваемого кредита. Максимальная сумма единовременно выдаваемого поручительства составляет 25 млн руб., а максимальный лимит поручительств - 50 млн руб., сумма предоставляемого кредита должна быть не менее 500 тыс. руб. Заёмщики выплачивают Фонду вознаграждение в размере от 0,75 до 1,5 \% от суммы поручительства (в 2018 г. максимальный размер вознаграждения составил $1 \%$ ) [8; 9]. В настоящее время Фонд сотрудничает с 20 банками-партнёрами, крупнейшими из которых являются Сбербанк, ВТБ, Россельхозбанк, Промсвязьбанк, Уральский банк реконструкции и развития и др. В 2018 г. 86 \% поручительств из общей суммы поручительств было предоставлено пяти крупнейшим кредиторам, о чём свидетельствуют данные табл. 2.

Таблица 2

\section{Состав кредиторов и объёмы кредитов и поручительств Гарантийного фонда содействия} кредитованию УР в 2018 году

\begin{tabular}{|l|c|c|c|}
\hline Название кредитора & $\begin{array}{c}\text { Объём поручительств, } \\
\text { млн руб. }\end{array}$ & $\begin{array}{c}\text { Объём кредитов, } \\
\text { млн руб. }\end{array}$ & $\begin{array}{c}\text { Доля поручительства } \\
\text { в сумме кредитов, \% }\end{array}$ \\
\hline ПАО «Сбербанк» & 302 & 634 & 47,6 \\
\hline ПАО «Промсвязьбанк» & 192 & 388 & 49,5 \\
\hline МКК «УФРП» & 79 & 163 & 48,5 \\
\hline АО «Россельхозбанк» & 68 & 253 & 26,9 \\
\hline ПАО «Банк Зенит» & 67 & 143 & 46,9 \\
\hline Прочие кредиторы & 115 & 263 & 43,7 \\
\hline Всего & 823 & 1844 & 44,6 \\
\hline
\end{tabular}

Одним из структурных подразделений Гарантийного фонда содействия кредитованию является Центр поддержки экспорта, который безвозмездно оказывает малому и среднему бизнесу услуги по ведению внешнеэкономической деятельности и выходу на зарубежный рынок, а именно: поиск заграничных партнёров, проверка их деловой репутации; консультации по различным вопросам ведения бизнеса; маркетинговые услуги, услуги переводчиков и т.д. За последние пять лет услугами Центра воспользовались более 500 компаний, было заключено более 100 экспортных контрактов, поддержано участие компаний более чем в 40 международных выставках.

Ещё одним направлением поддержки малого и среднего бизнеса Удмуртии является оказание инжиниринговых услуг в сфере внедрения инноваций, импортзамещающих производств и содействие развитию производственных предприятий Удмуртии с объёмом производства не менее 10 млн руб. в год. Услуги являются бесплатными при первом обращении за помощью и на условиях долевого финансирования при повторных обращениях.

Ряд услуг начинающим предпринимателям оказывает республиканский бизнес-инкубатор. Инкубатор предоставляет в аренду помещения на льготных условиях (250-500 руб. за м² в месяц), при этом в стоимость аренды входит само помещение, уже оснащённое мебелью и техникой, оплата коммунальных услуг, уборка и охрана помещения, электричество. Кроме того, резидент бизнес-инкубатора получает доступ ко всем материально-техническим, образовательным, научным ресурсам инкубатора, консалтинговую поддержку по финансовым и юридическим вопросам ведения бизнеса.

Таким образом, меры финансовой поддержки МСП в республике весьма разнообразны. На страницах сайтов соответствующих структур, рассмотренных в данной статье, можно найти все условия предоставления поддержки, получить бесплатную консультацию, рассчитать бизнес-план, найти партнёров по бизнесу, ознакомиться с наиболее успешными проектами в сфере МСП, воспользоваться калькулятором по микрозайму и получить другую информацию.

\section{СПИСОК ЛИТЕРАТУРЫ}

1. Федулова С.Ф. Сравнительный анализ реализации региональных целевых и ведомственных программ в Удмуртии и других субъектах федерации // Вестн. Удм. ун-та. Сер. Экономика и право. 2010. Вып. 4. С. 87.

2. Микрокредитная компания «Удмуртский фонд развития предпринимательства». URL: https://www.udbiz.ru/ upload/podprogramma_razvitie_malogo_i_srednego_predprinimatelstva_v_ur.pdf

3. Микрокредитная компания «Удмуртский фонд развития предпринимательства». URL: https://www.udbiz.ru/ napravleniya-podderzhki/ 
4. Микрокредитная компания «Удмуртский фонд развития предпринимательства». URL: http://www.fond.udbiz.ru/ o-fonde/otchety-fonda/godovoy_otchet_2017.pdf

5. Микрокредитная компания «Удмуртский фонд развития предпринимательства». URL: https://www.fond.udbiz.ru/ o-fonde/otchety-fonda/godovoy_otchet_2018.pdf

6. Микрокредитная компания «Удмуртский фонд развития предпринимательства». URL: https://www.udbiz.ru/ upload/msp_udbiz_2.pdf

7. Федеральная корпорация по развитию малого и среднего предпринимательства. URL: https://corpmsp.ru/ finansovaya-podderzhka/lizingovaya-podderzhka/

8. Гарантийный фонд содействия кредитованию малого и среднего предпринимательства Удмуртской Республики. URL: https://www.gfskur.ru/businessmen/pr1/

9. Гарантийный фонд содействия кредитованию малого и среднего предпринимательства Удмуртской Республики. URL: https://www.gfskur.ru/index/presentation/

Поступила в редакцию 12.11.2019

Федулова Светлана Федоровна, кандидат экономических наук, заведующий кафедрой финансов, учёта и математических методов в экономике, доцент Института экономики и управления

ФГБОУ ВО «Удмуртский государственный университет»

426034, Россия, г. Ижевск, ул. Университетская, 1 (корп. 4)

E-mail: fin@inem.uni.udm.ru

\section{S.F. Fedulova}

FINANCIAL SUPPORT OF SMALL AND MEDIUM-SIZED BUSINESSES IN THE UDMURT REPUBLIC

DOI: 10.35634/2412-9593-2019-29-6-771-775

The article discusses types and methods of funding small and medium business (SMB) in the Udmurt Republic. Funds and financial organizations as well as terms of their financial backup are in the focal point of the article. The author pays attention to the regional program "Development of small and medium-sized entrepreneurship in Udmurt Republic". The article focuses on terms and conditions of microloans, tenders, contract loans, intermediary services in bank guaranties, grace lease for equipment, grants for projects to support import phase-out that will support small and medium-sized enterprises. This funding is allocated by the "Udmurt Fund for the development of entrepreneurship". The analysis was carried out to calculate funding volumes, a number of project applications and projects financed and to identify the composition of financing for small and medium businesses which is allocated by the "Fund for the development of entrepreneurship" in relation to industries. The article studies the composition of creditors and loan and collateral volumes that are engaged by the Loan Guarantee Fund for SMEs. The author submits the types of financial backup for SMBs provided by the business incubator (grace lease for premises, business financial and legal consultancy).

Keywords: small and medium-sized enterprises, financial backup, microloans, tenders financing, contract loans, intermediary in bank guarantees, projects grants.

Received 12.11.2019

Fedulova S.F., candidate of economics, Head of Department of Finance, accounting and mathematical methods in economics, associate professor Institute of Economics and Management

Udmurt State University

Universitetskaya st., 1/4, Izhevsk, Russia, 426034

E-mail: fin@inem.uni.udm.ru 